Katrina Levine, ${ }^{1}$ John B. Luchansky, ${ }^{2}$

${ }^{1}$ North Carolina State University, Raleigh, NC 27695, USA

2U.S. Dept. of Agriculture, Wyndmoor, PA 19038 USA

${ }^{3}$ North Carolina Dept. of Health and Human Services,

Food Protection Branch, Gaston County, NC 28052, USA

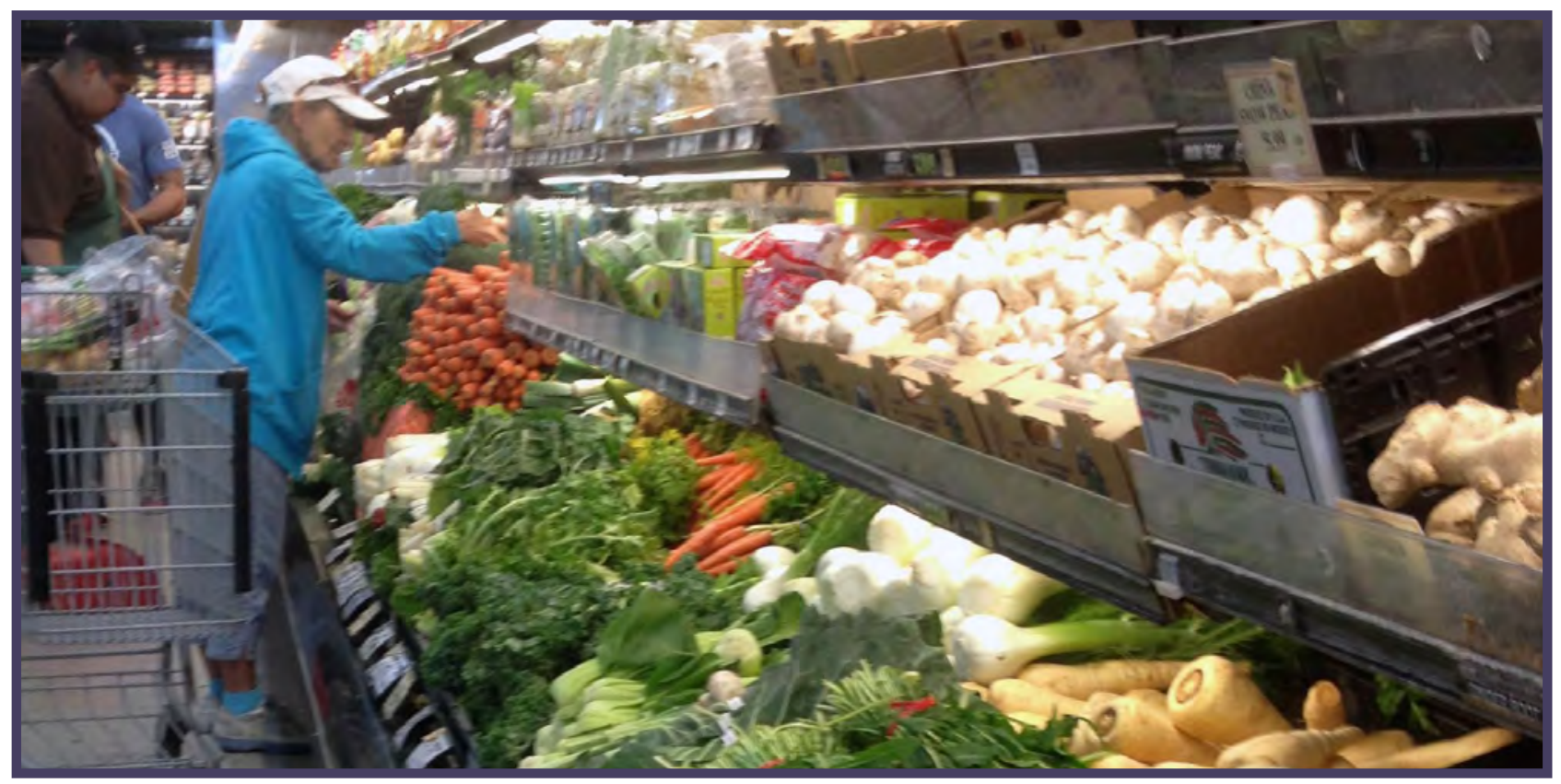

\title{
How Food Safety Savvy are Shoppers? Investigating and Impacting Consumers' Risk Identification Skills at Retail
}

\section{ABSTRACT}

Training videos were validated for improving consumers' identification of food safety risks at food retailers. Participants ( $n=62$ ) and an environmental health specialist [EHS] shopped at North Carolina grocery stores in October (baseline) and November (post-intervention) 2017 to collect food safety risk data using portable electronic devices. Experimental group participants viewed five videos about retail risk identification prior to the November shopping sessions and participated in focus groups thereafter. Risks were classified actual or perceived based on expert assessment. The EHS identified significantly more actual food safety risks than did the control group ( $n=34$ ) and experimental group $(n=28$ ) during both shopping sessions. The experimental group identified more actual than perceived food safety risks in November than in October (baseline: 19 of 40, 48\%; postintervention: 35 of 54, 65\%] compared with the controls. More actual food safety risks identified by the control and experimental groups agreed with EHS assessment during postintervention shopping [5 of $7,71 \%$ ] than during baseline shopping [ 2 of $7,29 \%$ ]. Focus groups supported a positive effect of viewing educational videos on shopper risk knowledge. These data established that training videos about retail food safety risk identification may help consumers improve identification of food safety risks in real time.

\section{INTRODUCTION}

Mitigation of foodborne illness is a shared responsibility along the farm to fork continuum, yet much of the burden is still placed on food retailers $(10,16,19,25,29,31)$. According to the 2017 U.S. Grocery Shopper Trends survey conducted by the Food Marketing Institute (10), "While consumers trust retailers to provide safe food, they are increasingly reliant on government institutions to ensure food is safe before it reaches stores shelves." Of the 2,145 primary grocery shoppers surveyed, people reported relying on themselves (57\%), the government (U.S. Food and Drug Administration [FDA], 56\%; U.S. Department of Agriculture [USDA], 51\%), and food stores (39\%) the most to "ensure what is bought at grocery is safe" (10). 
Consumers have high confidence in the safety of the U.S. food supply overall, especially with grocery stores; $87 \%$ of the 2,145 shoppers responding also reported they were "completely confident that the food in [their] grocery store is safe" (10). Regarding points along the food supply chain where food safety problems could occur, only $4 \%$ of the 2,145 shoppers stated that problems are most likely to occur at grocery stores, with the highest number (49\% of the 2,145 shoppers) implicating food processing or manufacturing plants as the most likely source of food safety failures (10).

Despite high confidence and trust in the safety of food at retail stores, retail grocery stores are not immune to food safety issues, and 648 outbreaks, 10,917 illness, 890 hospitalizations, and 19 deaths between 1998 and 2017 were linked to contaminated food purchased at grocery stores (6). Although not all illnesses are linked to grocery store food employee practices, studies of retail delis highlight inadequate sanitation practices as a risk factor (4, 22). Employees also contribute to product contamination at grocery stores, for example, by excessive handling of leafy greens $(7,30)$.

Consumers frequently cite food safety as an important factor impacting their food purchases and have cited bacteria as the most important food safety issue, followed closely by carcinogens or cancer-causing chemicals in foods $(9,17,29)$. Despite the importance placed on food safety, consumers often lack knowledge of foodborne illness risks, especially related to where they purchase food, and were only minimally aware of food safety risks associated with deli products (41). Although produce remains the top vehicle linked to foodborne outbreaks (27), consumers still perceive fresh produce as low risk for contamination $(20,46)$. The 2016 FDA Food Safety Survey highlighted the greater concern consumers have for contamination in raw chicken or beef than in raw vegetables (20). People also tend to perceive familiar risks as less severe than unfamiliar ones (13), suggesting that a consumer's own food handling practices would be perceived as less risky than another person's food handling practices. Although consumers have reported not seeing themselves as contributing to the potential for foodborne illness while shopping, research supports the fact that consumers contribute to contamination in grocery stores and farmers' markets (2, $28,40)$.

The present study was conducted with data gathered during two previous studies exploring food safety risk perceptions at grocery stores $(21,24)$. The goal was to better understand what factors or situations consumers see when grocery shopping in real time that concern them from a food safety perspective. We also developed interventions (i.e., educational videos) to help consumers becomes more aware of food safety risks at food retailers. A series of five short videos, approximately $2 \mathrm{~min}$ each, were created by Extension Service personnel for consumers to educate about factors and situations that could potentially impact food safety at grocery stores. Using portions of both the Centers for Disease Control and Prevention (CDC) contributing factors to foodborne illness (5) and the FDA 2013 Food Code (39) as a foundation for our expertderived risks, examples of factors potentially contributing to foodborne illness included (i) cross-contamination, (ii) inadequate temperature control, (iii) poor worker personal hygiene, and (iv) insufficient store sanitation. Each video featured a different store department. Finished videos were uploaded to a private YouTube channel (http://www. youtube.com) for viewing by the research team and the participants in the experimental group. Research questions addressed (i) whether consumers were able to identify food safety risks in real time when shopping at retail food stores and whether consumer perceptions differed from those of a trained food safety expert and (ii) whether viewing a series of short videos impacted consumers' abilities to identify food safety risks when shopping at retail food stores.

\section{MATERIALS AND METHODS Shopping protocol}

The protocol for this study was reviewed and accepted under North Carolina State University (NCSU) Institutional Review Board protocol 12273. The shopping protocol, survey questions (Fig. 1), and data collection device were pilot tested in September 2017. Participants were recruited for two shopping sessions, one in October (i.e., baseline) and the other in November (i.e., post-intervention) 2017, at one of three retail grocery stores in Wake County, North Carolina. Potential participants were recruited through targeted advertisements posted to social media. All participants met the following inclusion criteria: (i) $\geq 18$ years of age, (ii) primary food shopper, (iii) shops at grocery stores, (iv) access to the Internet to complete the recruitment survey and to view online educational videos using YouTube, (v) valid e-mail address, (vi) transportation to all of the potential food retailers, (vii) no previous food safety training, and (viii) no participation in any grocery shopping or cooking research studies at NCSU within the past 2 years. Demographic information collected through the screening survey was used to help identify potential participants as an approximately representative sample based on 2010 U.S. Census data (37). Study materials are available at go.ncsu.edu/foodsafetysavvy. Participants in this study were defined as citizen science data collectors because they were acting as untrained individuals, with all the biases of a consumer with respect to risk perceptions. This approach was used to collect perception data in the field and to evaluate actual risks.

From among the 673 potential participants who completed the survey, we selected 64 "qualified" shoppers (i.e., 32 for the control shopping group and 32 for the 


\section{In the PRODUCE section, do you see anything that concerns you in terms of food safety?}

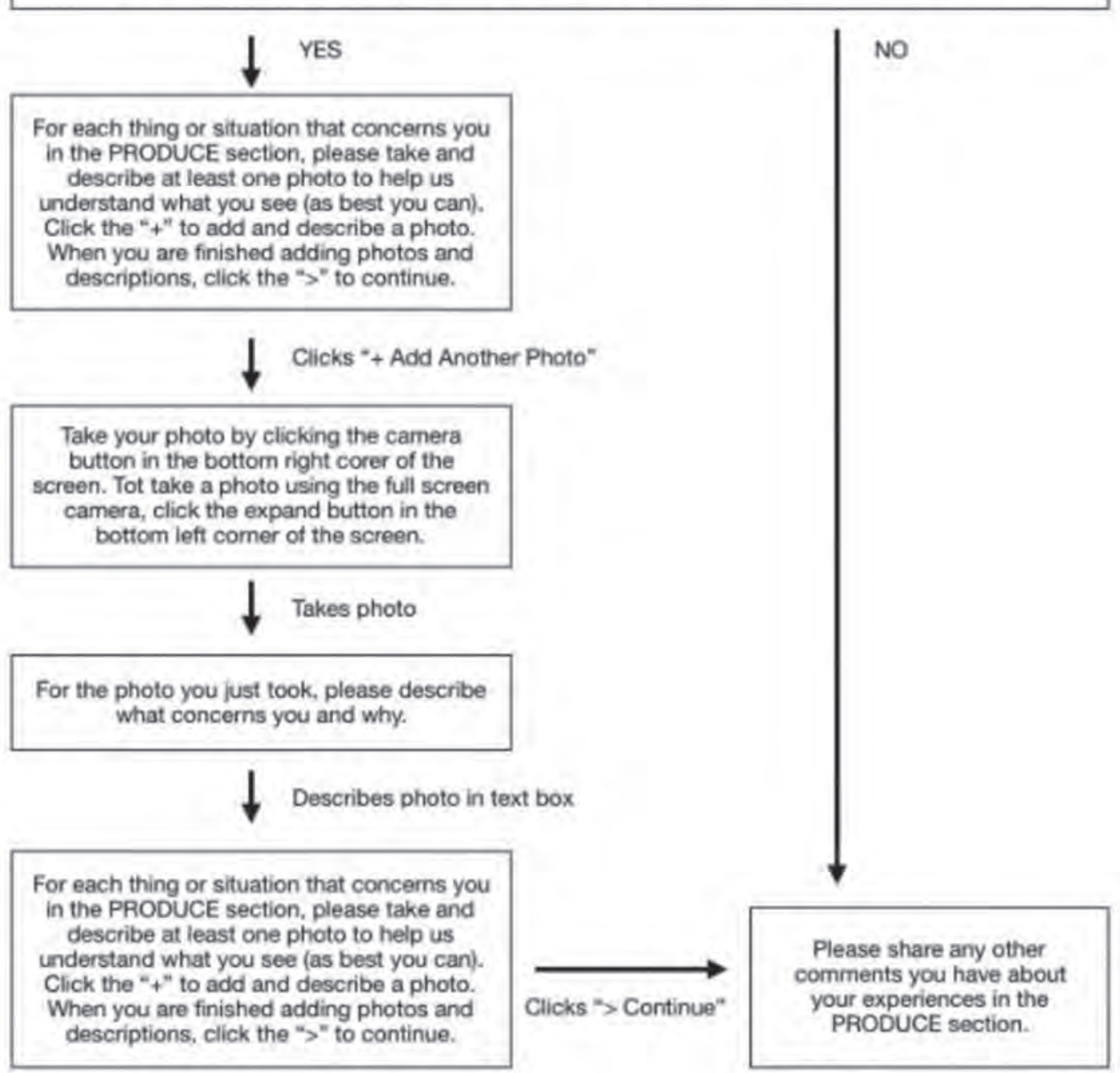

FIGURE 1. Flow of each section of questions in the data collection survey, with the produce department section as an example.

experimental shopping group) on a first-come, first-served basis to accommodate the required demographic targets so the sample set could be considered representative of the U.S. population based on the 2010 census (37). All recruited participants were scheduled for two shopping sessions: an initial baseline session (October 2017) and a second post-intervention session (November 2017). Participants were randomized into control and experimental shopping groups by the research team after the baseline shopping session, with a goal of $>30$ participants per group (total of $>60$ study participants), based on the assumptions of the central limit theorem for normally distributed populations (15). Prior to the November shopping sessions, participants in the experimental group were invited to view a series of five training videos (ca. 2 min each) and to subsequently participate in a focus group (in-person debriefing session) approximately 1 week after the post-intervention shopping sessions. This focus group was used to provide feedback on the videos from participants who had already experienced the shopping event. Each participant was scheduled for one 90-min time slot each for baseline and post-intervention shopping. Participant time slots were staggered to start every $10 \mathrm{~min}$ to reduce the chances of participants interacting with each other while shopping.

Three grocery stores were selected for the study for research team convenience and to optimize the diversity of participant shopping experiences within Wake County. 
Using a free online random number generator (36), stores were randomly assigned a date for data collection for baseline and post-intervention shopping.

A survey administered on a mobile electronic device (iPod Touch, Apple, Cupertino, CA) was used during grocery shopping sessions to enable the citizen science data to be collected on individual participant food safety perceptions. Similar studies have utilized surveys on mobile devices to collect data about consumer food shopping experiences and practices $(1,2,28)$. Data for the present study were collected with the iSURVEY app (Harvest Your Data, Wellington, New Zealand) administered on an iPod Touch. The survey instructions listed five departments to visit while shopping: produce, deli, meat and poultry, seafood, and checkout. These departments were chosen to represent food items commonly implicated in foodborne illness outbreaks (e.g., produce, meat, poultry, and deli foods) and are regulated by local health departments. The checkout areas were included because of previous research on transfer of pathogens from conveyor belts to foods at the checkout counter (44). Five question sections, each about a different department but intentionally redundant, were presented to participants (Fig. 1). Each section incorporated skip logic and loop question functions (35) so that each participant did not necessarily receive all questions in a section. Participants were required to answer the first and last question in each section for each store department. When asked to take a photo, participants were offered the option of taking multiple photos within a section for a given department and providing an explanation for each photo by use of a loop question function.

At the baseline shopping sessions, participants met individually with research team members at a central location near the store prior to entering the grocery store to shop. At that time, participants also received a packet containing a \$50 gift card to the grocery store, a diagram of the layout of the store with a suggested path for collecting data while shopping, a copy of the NCSU consent form, and a letter signed by the principal investigators explaining research activities to share with store management if necessary. Participants then shopped at the store and used the iPod Touch to document observations and complete the survey. "Food safety" was not defined for participants before, during, or after completing the study. Postintervention shopping was conducted in a manner similar to that of baseline shopping, except that shoppers in the experimental group viewed training videos prior to shopping in November 2017.

\section{Expert standard}

An environmental health specialist (EHS) from the North Carolina Department of Health and Human Services (Gaston County, Gastonia, NC) provided the expert standard. The EHS was part of the research team and helped to develop and review the training videos. Participant responses were compared with the findings of the EHS for determining agreement with food safety risks as identified by the expert. The EHS entered the store approximately 15 min prior to the first shoppers scheduled during each of the 18 shopping groups. The EHS used the same iPod Touch and questionnaire as used by the control and experimental shopping groups to collect information. The EHS was instructed to apply knowledge of grocery store inspection regulations to the areas of the store the shoppers were limited to.

\section{Intervention}

Five 2-min videos were created by the research team to educate consumers about factors and situations that could impact food safety at grocery stores. Using portions of both the CDC contributing factors to foodborne illness (5) and the FDA 2013 Food Code (39) as a foundation for our expert-derived risks, examples of potential contributing factors for foodborne illness included (i) cross-contamination, (ii) inadequate temperature control, (iii) poor worker personal hygiene, and (iv) insufficient store sanitation. Each video featured a different store department. Finished videos were uploaded to a private YouTube channel for viewing by the research team and experimental group participants. A snapshot from the produce department video is shown in Figure 2. Approximately 1 month following the baseline shopping session, participants in the experimental group received an e-mail message with a link to access to the educational videos on YouTube. Participants in the experimental group were also asked to participate in a focus group after their post-intervention shopping session. Three focus groups were held in Raleigh, NC approximately 1 week after the November shopping sessions with a group size of 8 to 12 participants per focus group according to published recommendations (34). During the focus group meetings, the research team solicited feedback about the data collection process and the quality, content, and effectiveness of the intervention materials. The research team also solicited feedback about the effectiveness of the intervention as a catalyst for longstanding behavioral change. Each focus group meeting lasted approximately $60 \mathrm{~min}$. All participants were compensated for their participation in the study with gift cards totaling \$200 to either Amazon (Seattle, WA) or the grocery store of their choice (from the study stores used as shopping locations; store names not disclosed for confidentiality).

\section{Statistical analyses}

Quantitative analyses included paired, equal variance, and unequal variance $t$ tests conducted in Excel (Microsoft, Redmond, WA). Results were considered significant at $P<0.05$. Determination of actual versus perceived risk situations was based on the current body of knowledge 


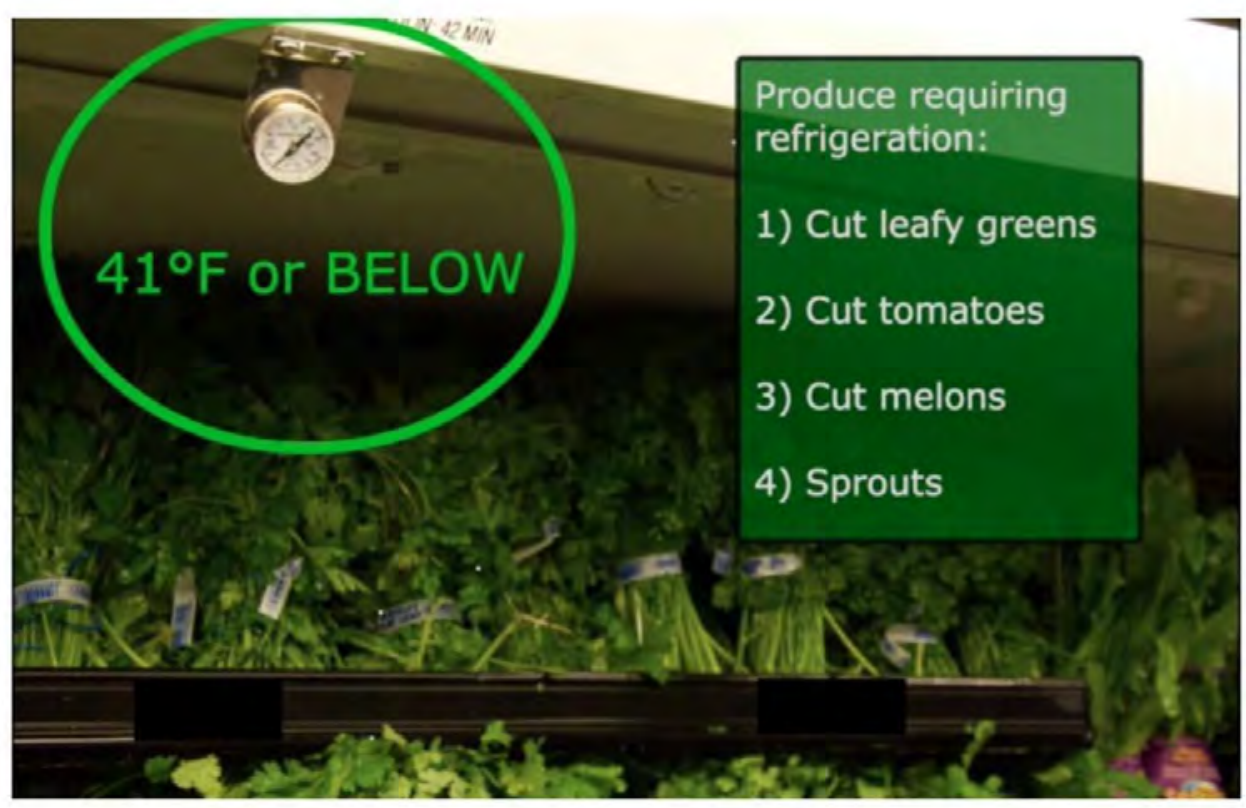

FIGURE 2. Snapshot from the produce department intervention video.

related to food safety risks at the retail level, including the FDA 2013 Food Code, FDA Trend Analysis Report (38), and the North Carolina Food Establishment Inspection Report form (26). Actual food safety risks were defined as outlined by Levine et al. (21) and were classified according to the Inspection Report codes (26). Perceived food safety risks were defined also as outlined by Levine et al. (21) and as all other identified factors or situations not falling within the definition of actual food safety risks. The food safety risks identified by the EHS were considered actual factors or situations. Qualitative data collected from focus groups included coding of transcripts after analysis of thematic content to develop themes (3). To facilitate the collection of data from focus group participants, these meetings were recorded with consent from participants and transcribed by an online service (TranscribeMe, San Francisco, CA). Deidentified transcripts are available at go.ncsu.edu/ foodsafetysavvy.

\section{RESULTS}

\section{Baseline and post-intervention shopping sessions}

Of the 69 participants recruited for this study, 66 completed both shopping sessions ( 36 in the control group and 30 in the experimental group). After $t$-tests, four outliers were removed because at least one result from each outlier participant was greater than three standard deviations above the group mean. Demographics for the remaining 62 participants ( 34 control and 28 experimental) are provided in Table 1. A mean of 3.1 participants (range, 0 to 7 ) from the experimental and 3.8 participants (range, 0 to 7 ) from the control group participated in each baseline and post-intervention session, for a mean of 6.9 total participants per shopping group (range for both groups, 5 to 10). We assumed that participants and the EHS shopping in the same store during the same session were most likely to witness the same food safety risks and situations within the prescribed 3-h session.

Participants identified 67 total potential (perceived and actual) food safety risks while shopping during the baseline session: 40 (60\%) were identified by the experimental group, and 27 (40\%) were identified by the control group (Table 2). During postintervention shopping, participants identified 81 total potential food safety risks: 54 (67\%) were identified by the experimental group, and 27 (33\%) were identified by the control group. The EHS identified 87 total food safety risks during the baseline shopping session and 102 during the postintervention shopping session.

Participants in both groups identified more perceived (21 in the experimental group; 20 in the control group) than actual (19 in the experimental group; 7 in the control group) food safety risks during the baseline shopping session, and only the control group identified more perceived (17) than actual (10) food safety risks while shopping postintervention (Table 2). Participants in the experimental group identified a higher number and percentage of actual food safety risks than perceived risks at postintervention shopping than at baseline shopping (baseline: 19 of 40, 48\%; post-intervention: 35 of 54, 


\section{TABLE 1. Demographic characteristics of survey and focus group participants in a study}

of consumer risk perception at retail food stores

\begin{tabular}{|c|c|c|c|c|}
\hline \multirow[t]{2}{*}{ Characteristic $^{a}$} & \multicolumn{2}{|c|}{$\begin{array}{l}\text { Total survey respondents } \\
\qquad(n=62)\end{array}$} & \multicolumn{2}{|c|}{$\begin{array}{l}\text { Focus group } \\
\quad(n=28)\end{array}$} \\
\hline & No. & $\%^{b}$ & No. & $\%$ \\
\hline \multicolumn{5}{|l|}{ Race } \\
\hline White & 43 & 69 & 21 & 75 \\
\hline Black or African American & 12 & 19 & 3 & 11 \\
\hline Asian & 5 & 8 & 2 & 7 \\
\hline Native Hawaiian or other Pacific Islander & 1 & 2 & 1 & 4 \\
\hline American Indian or Alaska Native & 1 & 2 & 1 & 4 \\
\hline \multicolumn{5}{|l|}{ Hispanic/Latino } \\
\hline No & 54 & 87 & 26 & 93 \\
\hline Yes & 8 & 13 & 2 & 7 \\
\hline \multicolumn{5}{|l|}{ Age (yr) } \\
\hline $18-34$ & 24 & 39 & 9 & 32 \\
\hline $35-54$ & 26 & 42 & 9 & 32 \\
\hline$\geq 55$ & 12 & 19 & 10 & 36 \\
\hline
\end{tabular}

\section{Highest level of education}

\begin{tabular}{|c|c|c|c|c|}
\hline Less than high school, high school graduate, or GED & 4 & 6 & 2 & 7 \\
\hline Some college or 2-yr degree & 15 & 24 & 7 & 25 \\
\hline College degree & 29 & 47 & 14 & 50 \\
\hline Postgraduate degree & 14 & 23 & 5 & 18 \\
\hline
\end{tabular}

\section{Annual household income}

\begin{tabular}{l|c|c|c|c}
\hline$<\$ 25,000$ & 7 & 11 & 2 & 7 \\
\hline$\$ 25,000-49,999$ & 13 & 21 & 4 & 14 \\
\hline$\$ 50,000-74,999$ & 22 & 35 & 14 & 50 \\
\hline$\$ 75,000-99,999$ & 8 & 13 & 3 & 11 \\
\hline$\$ 100,000-124,999$ & 8 & 13 & 3 & 11 \\
\hline$\$ 125,000-149,000$ & 1 & 2 & 0 & 0 \\
\hline$\$ 150,000-174,999$ & 1 & 2 & 1 & 4 \\
\hline$\$ 175,000-199,999$ & 2 & 3 & 1 & 4 \\
\hline
\end{tabular}

\section{Children in household}

\begin{tabular}{l|l|l|l|l}
\hline No & 37 & 60 & 17 & 61 \\
\hline Yes & 25 & 40 & 11 & 39 \\
\hline
\end{tabular}

\section{Are you or any members of your household ...}

\begin{tabular}{|c|c|c|c|c|}
\hline Pregnant & 1 & 2 & 0 & 0 \\
\hline Breastfeeding & 3 & 5 & 3 & 11 \\
\hline$\leq 5 \mathrm{yr}$ of age & 10 & 16 & 5 & 18 \\
\hline$\geq 60 \mathrm{yr}$ of age & 12 & 19 & 10 & 36 \\
\hline Diagnosed with diabetes or kidney disease & 4 & 6 & 7 & 25 \\
\hline Diagnosed with an allergy to any food or food ingredient & 7 & 11 & 2 & 7 \\
\hline
\end{tabular}

${ }^{a}$ Gender data were not collected. Demographic data for the environmental health specialist were not collected. ${ }^{b}$ All percentages have been rounded to the nearest whole integer; therefore, some results do not sum to $100 \%$.

'Multiple answers per respondent were possible. 


\section{TABLE 2. Identification of actual and perceived food safety risks that contribute to foodborne illness in food retail settings}

\begin{tabular}{|c|c|c|c|c|c|c|c|}
\hline \multirow[t]{3}{*}{ Survey time } & \multicolumn{7}{|c|}{ No. of respondents } \\
\hline & \multicolumn{3}{|c|}{ Experimental group $(n=28)$} & \multicolumn{3}{|c|}{ Control group $(n=34)^{a}$} & \multirow{2}{*}{$\begin{array}{c}\text { Expert } \\
(n=1)^{b}\end{array}$} \\
\hline & Actual & Perceived & All & Actual & Perceived & All & \\
\hline \multicolumn{8}{|l|}{ Baseline } \\
\hline Mean per session & 2.1 & 2.3 & 4.4 & 0.9 & 2.5 & 3.4 & 9.7 \\
\hline Mean per person & 0.7 & 0.8 & 1.4 & 0.2 & 0.6 & 0.8 & 87 \\
\hline Total & 19 & 21 & 40 & 7 & 20 & 27 & 87 \\
\hline \multicolumn{8}{|l|}{ Post-intervention } \\
\hline Mean per session & 3.9 & 2.1 & 6.0 & 1.1 & 1.9 & 3.0 & 11.3 \\
\hline Mean per person & 1.3 & 0.7 & 1.9 & 0.3 & 0.5 & 0.8 & 102 \\
\hline Total & 35 & 19 & 54 & 10 & 17 & 27 & 102 \\
\hline
\end{tabular}

${ }^{a}$ One session for the baseline had no control group participants.

${ }^{b}$ Food safety risks identified by the expert were considered to be actual.

TABLE 3. Differences in actual food safety risks identified by each group between baseline and post-intervention shopping sessions in a study of consumer risk perceptions in food retail settings

\begin{tabular}{l|c|c|c}
\multirow{2}{*}{ Group } & \multicolumn{2}{|c|}{ No. of risks identified (mean \pm SD) } & \multicolumn{1}{c}{$P_{\text {-value }}^{a}$} \\
\hline & Baseline $(n=9)$ & Post-intervention $(n=9)$ & 0.3 \\
\hline Expert $(n=1)$ & $9.7 \pm 3.2$ & $11.3 \pm 3.7$ & 0.2 \\
\hline Experimental $(n=28)$ & $2.1 \pm 2.3$ & $3.9 \pm 2.8$ & 0.8 \\
\hline Control $(n=34)$ & $0.9 \pm 1.7^{\mathrm{b}}$ & $1.1 \pm 1.3$ & \\
\hline
\end{tabular}

${ }^{a}$ All tests for equal variances except for those noted, where unequal variances test was used.

${ }^{b}$ Baseline values were based on eight instead of nine participants because one session had no control group participants.

65\%) (Table 2). Participants in the control group also identified a higher number and percentage of actual food safety risks compared with perceived risks during postintervention shopping than while baseline shopping (baseline: 7 of 27, 26\%; post-intervention: 10 of $27,37 \%$ ) (Table 2). However, the numbers of actual food safety risks identified were not significantly different between baseline and post-intervention shopping for either treatment group (experimental, $P=0.2$; control, $P=0.8$ ) (Table $3)$. The number of actual food safety risks reported by participants in the experimental and control groups were not significantly different $(P=0.2)$ for baseline shopping; however, they were significantly different $(P=0.01)$ for post-intervention shopping (Table 4). The expert, who also identified more actual food safety risks at post-intervention than at baseline (baseline: 87 risks; post-intervention: 102 risks), identified significantly more actual food safety risks than did participants in either the experimental or control groups at both baseline shopping sessions (experimental, $P=0.00003$; control, $P=0.000004)$ and post-intervention shopping sessions (experimental, $P=0.0002$; control, $P=$ 0.0000008) (Table 4).

The number of actual food safety risks identified per participant in the experimental group nearly doubled 


\section{TABLE 4. Differences in actual food safety risks identified between groups in a study of consumer risk perception in food retail settings}

\begin{tabular}{|c|c|c|c|c|c|c|}
\hline \multirow[t]{3}{*}{ Pairwise comparison } & \multicolumn{6}{|c|}{ No. of risks identified ${ }^{a}$} \\
\hline & \multicolumn{3}{|c|}{ Baseline $(n=9)$} & \multicolumn{3}{|c|}{ Post-intervention $(n=9)$} \\
\hline & Mean \pm SD & Total & Per person & Mean \pm SD & Total & Per person \\
\hline Experimental $(n=28)$ & $2.1 \pm 2.3$ & 19 & 0.7 & $3.9 \pm 2.8$ & 35 & 1.3 \\
\hline Control $(n=34)$ & $0.9 \pm 1.7^{b}$ & 7 & 0.2 & $1.1 \pm 1.3$ & 10 & 0.3 \\
\hline$P$-value ${ }^{c}$ & 0.2 & & & 0.01 & & \\
\hline Expert $(n=1)$ & $9.7 \pm 3.2$ & 87 & 87 & $11.3 \pm 3.7$ & 102 & 102 \\
\hline Experimental & $2.1 \pm 2.3$ & 19 & 0.7 & $3.9 \pm 2.8$ & 35 & 1.3 \\
\hline$P$-value & $<0.01$ & & & $<0.01$ & & \\
\hline Expert & $9.7 \pm 3.2$ & 87 & 87 & $11.3 \pm 3.7$ & 102 & 102 \\
\hline Control & $0.9 \pm 1.7^{b}$ & 7 & 0.2 & $1.1 \pm 1.3$ & 10 & 0.3 \\
\hline$P$-value & $<0.01^{c}$ & & & $<0.01$ & & \\
\hline
\end{tabular}

${ }^{a}$ Bold values indicate pairwise group comparisons that are significantly different at $P<0.05$ (95\% probability).

${ }^{b}$ Baseline values were based on eight instead of nine participants because one session had no control group participants.

${ }^{c}$ All tests for equal variances except for those noted, where unequal variances test was used.

Expert

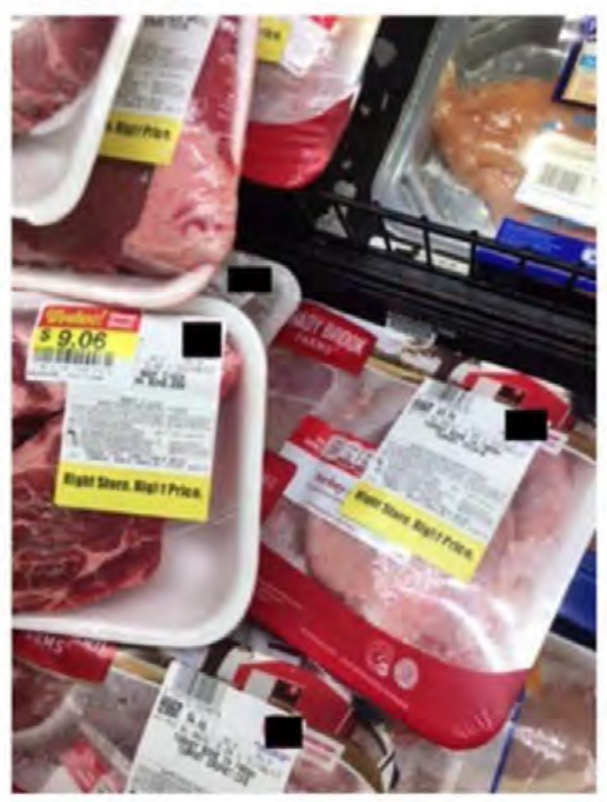

\section{Comment: "Commingling turkey} and beef"

\section{Participant}

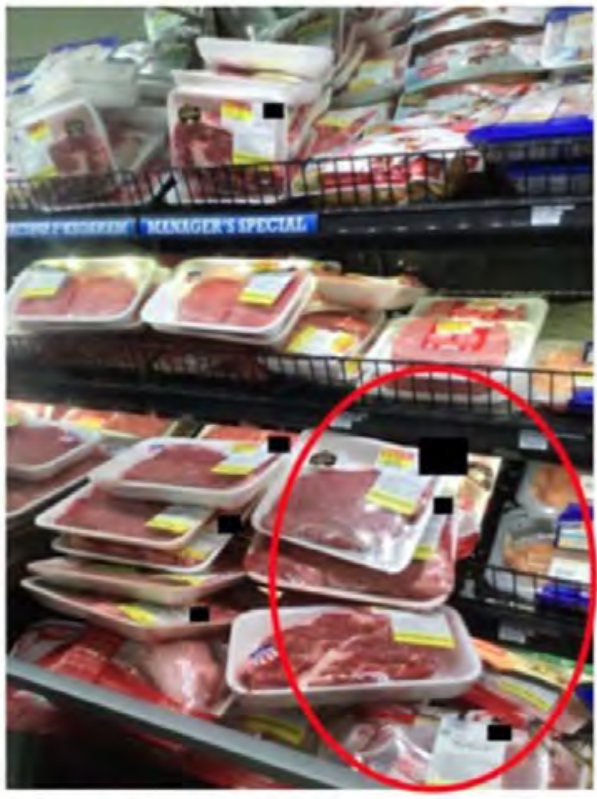

Comment: "This section was overflowing with several different meats. I'm concerned with cross contamination."

FIGURE 3. Comparison of expert and participant responses related to the same food safety risk. 


\section{TABLE 5. Examples of agreement between participants and the expert when identifying}

food safety risks in food retail settings

\begin{tabular}{|c|c|c|c|c|c|c|}
\hline Department & $\begin{array}{l}\text { Expert } \\
\text { comment }\end{array}$ & $\begin{array}{l}\text { Participant } \\
\text { comment }\end{array}$ & $\begin{array}{l}\text { Participant } \\
\text { group }\end{array}$ & $\begin{array}{l}\text { Concept from } \\
\text { video }\end{array}$ & $\begin{array}{l}\text { Factor } \\
\text { contributing } \\
\text { to foodborne } \\
\text { illness }\end{array}$ & $\begin{array}{l}\mathrm{NC} \\
\text { inspection } \\
\text { code }\end{array}$ \\
\hline \multicolumn{7}{|l|}{ Post-intervention } \\
\hline Meat and poultry & $\begin{array}{l}\text { Comingling } \\
\text { turkey and beef }\end{array}$ & $\begin{array}{l}\text { This section was } \\
\text { overflowing with } \\
\text { different meats. } \\
\text { I'm concerned } \\
\text { with cross- } \\
\text { contamination }\end{array}$ & Control & $\begin{array}{c}\text { Meat and } \\
\text { poultry: } \\
\text { separation of } \\
\text { meat and poultry } \\
\text { species }\end{array}$ & $\begin{array}{l}\text { Contaminated } \\
\text { equipment or } \\
\text { prevention of } \\
\text { contamination }\end{array}$ & 13 \\
\hline Meat and poultry & $\begin{array}{c}\text { Overstacking of } \\
\text { meat }\end{array}$ & $\begin{array}{l}\text { Meat piled on } \\
\text { top of each } \\
\text { [other] }\end{array}$ & Experimental & $\begin{array}{l}\text { Not specifically } \\
\text { covered }\end{array}$ & $\begin{array}{c}\text { Improper } \\
\text { holding time and } \\
\text { temp }\end{array}$ & 20 \\
\hline Produce & $\begin{array}{c}\text { Unclean storage } \\
\text { area }\end{array}$ & $\begin{array}{l}\text { The bottom of } \\
\text { the shelf is lined } \\
\text { but it's very wet } \\
\text { and "muddy" } \\
\text { looking }\end{array}$ & Experimental & $\begin{array}{c}\text { Produce: } \\
\text { cleanliness of } \\
\text { food storage } \\
\text { areas }\end{array}$ & $\begin{array}{l}\text { Inadequate } \\
\text { cleaning and } \\
\text { sanitation }\end{array}$ & 47 \\
\hline Seafood & $\begin{array}{l}\text { Cooked and raw } \\
\text { seafood touching }\end{array}$ & $\begin{array}{c}\text { Salad among } \\
\text { uncooked } \\
\text { seafood .... } \\
\text { Ready-to-eat } \\
\text { salad beside } \\
\text { uncooked lobster }\end{array}$ & Control & $\begin{array}{c}\text { Seafood: } \\
\text { separation of raw } \\
\text { and ready-to-eat } \\
\text { products }\end{array}$ & $\begin{array}{l}\text { Contaminated } \\
\text { equipment or } \\
\text { prevention of } \\
\text { contamination }\end{array}$ & 13 \\
\hline Meat and poultry & $\begin{array}{l}\text { Leaking } \\
\text { packages }\end{array}$ & $\begin{array}{l}\text { Not stored on } \\
\text { clean shelves }\end{array}$ & Experimental & $\begin{array}{c}\text { Meat and } \\
\text { poultry: package } \\
\text { integrity and } \\
\text { leaks }\end{array}$ & $\begin{array}{l}\text { Contaminated } \\
\text { equipment or } \\
\text { prevention of } \\
\text { contamination }\end{array}$ & 11,47 \\
\hline
\end{tabular}

\section{Baseline}

\begin{tabular}{|c|c|c|c|c|c|c|}
\hline Meat and poultry & $\begin{array}{l}\text { Meat residue on } \\
\text { shelving }\end{array}$ & $\begin{array}{l}\text { Dirty, chipped } \\
\text { shelves for the } \\
\text { meat }\end{array}$ & Experimental & $\begin{array}{c}\text { Produce: } \\
\text { cleanliness of } \\
\text { food storage } \\
\text { areas }\end{array}$ & $\begin{array}{l}\text { Inadequate } \\
\text { cleaning and } \\
\text { sanitation }\end{array}$ & 47 \\
\hline Meat and poultry & $\begin{array}{l}\text { Meat residue on } \\
\text { shelving }\end{array}$ & $\begin{array}{l}\text { Shelf conditions } \\
\text { unappealing }\end{array}$ & Experimental & $\begin{array}{c}\text { Produce: } \\
\text { cleanliness of } \\
\text { food storage } \\
\text { areas }\end{array}$ & $\begin{array}{l}\text { Inadequate } \\
\text { cleaning and } \\
\text { sanitation }\end{array}$ & 47 \\
\hline
\end{tabular}


TABLE 6. Actual food safety risks identified by each group at specific departments within grocery stores in a study of consumer risk perception in food retail settings ${ }^{a}$

\begin{tabular}{|c|c|c|c|c|c|c|c|}
\hline \multirow[t]{3}{*}{ Department } & \multicolumn{7}{|c|}{ No. of risks } \\
\hline & \multicolumn{3}{|c|}{ Baseline } & \multicolumn{3}{|c|}{ Post-intervention } & \multirow{2}{*}{ Tota } \\
\hline & Expert & Experimental & Control & Expert & Experimental & Control & \\
\hline Produce & 26 & 4 & 1 & 27 & 14 & 0 & 72 \\
\hline Deli & 21 & 6 & 1 & 33 & 7 & 5 & 73 \\
\hline Meat and poultry & 24 & 6 & 2 & 30 & 7 & 3 & 72 \\
\hline Seafood & 12 & 0 & 0 & 8 & 4 & 1 & 25 \\
\hline Checkout & 4 & 3 & 3 & 4 & 3 & 1 & 18 \\
\hline Total & 87 & 19 & 7 & 102 & 35 & 10 & 260 \\
\hline
\end{tabular}

${ }^{a}$ Total of 62 participants.

from 0.7 at baseline to 1.3 at post-intervention shopping, but this number increased only slightly from 0.2 to 0.3 for participants in the control group and remained below the number identified by participants in the experimental group (Table 2). The EHS identified more actual food safety risks (102) than did the experimental (1.3) and control (0.3) groups at the post-intervention shopping sessions. The proportion of actual food safety risks identified per participant increased from 50 to $68 \%$ in the experimental group (baseline: 0.7 ; post-intervention: 1.3 ) and 25 to $38 \%$ in the control group (baseline: 0.2; post-intervention: 0.3 ).

Participants identified seven food safety risks that agreed with the EHS assessment during the course of the study. More actual food safety risks identified by both the control and experimental groups were in agreement with those identified by the EHS at post-intervention (five of seven, $71 \%$ ) than at baseline (two of seven, $29 \%$ ). Of the 81 data points recorded at post-intervention when participants indicated they saw something that concerned them in terms of food safety (experimental: 54 risks; control: 27 risks), which included both perceived and actual food safety risks, participants in the experimental group agreed with the EHS assessment in 6\% of those instances ( 3 risks) and those in the control group agreed with $7 \%$ (2 risks). When considering only actual food safety risks identified during post-intervention shopping (experimental: 35 risks; control: 10 risks), participants in the experimental group agreed with the EHS assessment in 9\% of those instances ( 3 risks) and those in the control group agreed with 20\% ( 2 risks). Participants in both groups were most likely to identify at least one food safety risk in the meat and poultry department that was also identified by the EHS (five of seven risks, $71 \%$ ), and they were least likely to identify at least one food safety risk at checkout (0 risks). An example of agreement between a participant and the EHS is shown in Figure 3, where comingling and the resulting likelihood of cross-contamination were identified by both parties. Table 5 displays each of the seven food safety risks that were identified by both shoppers and the EHS, with corresponding comments.

Data were also categorized and analyzed by store department (Table 6). Of the 260 actual food safety risks identified, including those identified by the EHS, most were identified in the deli department ( 73 of 260 , $28 \%$ ), followed by the produce ( 72 of $260,28 \%$ ) and meat and poultry (72 of $260,28 \%)$ departments. These three departments accounted for approximately $83 \%$ of all the actual food safety risks identified. Participants consistently identified the most actual risks (produce: 19; deli: 19; meat and poultry: 18) and perceived risks (produce: 29; deli: 17; meat and poultry: 14) in these three departments. In the produce and seafood departments, participants identified more perceived risks (produce: 29; seafood: 15) than actual risks (produce: 19; seafood: 5).

Participants in the experimental group identified more actual food safety risks in the produce, deli, meat and poultry, and seafood departments at post-intervention than at baseline shopping (Table 6). Paired $t$-tests for individual participants before and after viewing the training videos revealed that the increase in actual risk identification was significant for produce (baseline: 4 risks; post-intervention: 14 risks; $P=0.02$ ) and seafood (baseline: 0 risks; post-intervention: 4 risks; $P=0.04$ ). For no individual participants in either group were significant differences in the mean number of identified actual food safety risks obtained between baseline and post-intervention shopping. 


\section{Focus groups}

Twenty-eight participants from the experimental group completed the debriefing session as a secondary analysis step following the second shopping event. Three focus group meetings were conducted on a single day in November 2017 approximately 1 week after the postintervention shopping sessions, and each included 9 or 10 participants and were conducted to gain summative feedback on the educational videos. Table 1 provides the demographic characteristics of focus group participants. Overall, participants found the intervention videos useful and informative. Participants felt more aware of food safety issues in grocery stores after watching the videos: "now, since watching those videos, it made me more aware of what I should be doing." Although some participants noted having some foundational knowledge related to food safety that they applied during their shopping trips, many acknowledged not knowing much about the information shown in the videos: "I didn't know what some of the really scary stuff was until I watched the video."

Key themes directly resulting from watching the videos included new awareness of retail food storage temperatures and cleanliness of food storage areas. After viewing the videos, participants paid more attention to the cleanliness of food storage areas and surfaces and the temperatures of hot and cold food storage areas. Several participants reported understanding that sight and touch are not reliable indicators of food safety: "I've already thought about temperature, but the way that I thought that I was assessing it the first time there was by touching things to see if they were cold. That is obviously not reliable measurement."

Two additional themes of interest emerged. The first was a difference in the perception of food safety, specifically cleanliness, between stores that appeared "old" versus stores that appeared "new"; stores that appear to be new were often perceived as being cleaner than those that appear to be old. The second theme was a skepticism of how food is handled prior to customers selecting and purchasing food items, especially items located in the salad bar.

\section{DISCUSSION}

Microbial contamination leading to foodborne illness can originate at multiple points in the food system, including at the retail level $(4,25,30)$. Consumers could impact their risk of foodborne illness from potentially unsafe foods and beverages purchased at grocery stores if provided adequate information to identify and act upon potential foodborne illness risks, assuming that consumers would handle, store, and/or prepare foods properly at home. With regards to an assumed gap between consumer and expert perceptions of food safety, we evaluated whether shoppers could identify the same risky situations impacting food safety (food safety risks) at food retailers as were identified by an expert and whether identification improved as the result of an intervention (i.e., training videos) showing food safety best practices within grocery stores. Similar studies have included use of a research team to collect real-time data with a mobile device instead of allowing consumers as citizen scientists to collect specific data in real time (2, $28,40)$. Data collected directly by the consumer is viewed and recorded through their lens and impacted by their personal experiences and biases instead of those of the researcher, allowing for a better understanding of the consumer perspective. Data collection in real time further promotes understanding of the consumer's thoughts and potential actions as a situation or event is occurring, such as when choosing or not choosing a product in a grocery store for a specific reason. Similar data collection methods and strategies in research studies could lead to interventions that more effectively promote positive and lasting behavior change.

The results of this study verify the existence of a gap between what consumers perceive and what experts perceive as risks impacting food safety at grocery stores. In our study, the expert (i.e., the EHS) identified significantly more actual food safety risks than did the consumers, regardless of whether the five training videos had been viewed by the shoppers in the experimental group. Findings from other research and our previous study (21) have verified this difference in perception $(13,14,42,43,46)$. Food safety experts view the safety of food from a technical risk standpoint $(32,33)$. The 2013 FDA Food Code (39), which is developed with input from a team of food safety experts, provides guidance on the best practices for safe food handling in food retail settings. The average consumer is not familiar with this manual unless they have worked in a food retail setting. The Code prohibits retail employee food handler actions that may increase the risk of foodborne illness, including eating or drinking, touching of hair or body, and handling ready-to-eat foods with bare unwashed hands, because of the risk of cross-contamination. Despite food safety training and knowledge of food safety best practices, such as provided to an employee food handler, food handlers still do not reliably use safe food-handling practices $(7,23,47)$.

Slovic (32) suggested that consumers use unsafe food handling practices because they do not focus strictly on the quantitative risks of foodborne illness associated with unsafe food handling behaviors but rather incorporate psychological and social perceptions of risk into their mindset and actions. In several observational studies, consumers practiced unsafe food handling behaviors when purchasing food $(2,28,40)$. Paulin et al. (28) observed the food safety behaviors of consumers shopping in grocery stores in Rhode Island and found that these shoppers used unsafe food handling and hygiene behaviors that increased the potential for produce contamination, including (i) manipulating produce and putting it back on the shelf, (ii) 
eating while shopping, (iii) licking their fingers to open a plastic bag, and (iv) touching their hair, another part of the body, clothing, or a cell phone before touching produce. Poor food handling practices have also been observed among consumers when shopping for fresh produce and other food products at farmers' markets $(2,40)$. In a representative U.S. sample of 937 individuals, Yu et al. (46) found that $86 \%$ of participants considered fresh-cut produce risky or very risky for harboring foodborne pathogens, but $71 \%$ reported that the fresh-cut produce they purchased was unlikely or very unlikely to be contaminated with foodborne pathogens. Researchers speculated that this perception of a low probability of getting foodborne illness from purchasing and consuming fresh-cut produce may be due to the psychological phenomenon called optimistic bias, wherein people comparing themselves with others believe they are less likely to experience negative events and more likely to experience positive events $(11,46)$. Consumers also exhibit optimistic bias in terms of their own food handling, believing that the likelihood of their own behavior being the source of their foodborne illness is lower than the likelihood of someone else being the source of their foodborne illness $(13,42)$. This rationale stems from the theory that people fear unfamiliar risks more than familiar ones (13). Webster et al. (43) explored expert and consumer perspectives in a risk ranking task and discovered that experts and consumers disagreed most in the areas of awareness and trust for issues they ranked the highest. Another potential factor influencing the gap between consumer and expert perceptions of food safety risks could be that consumers may be less interested and/or less aware of food safety risks in a noncrisis (i.e., non-outbreak) situation. Consumers trust their grocery stores to provide safe food and assume a status quo level of food safety. They may pay more attention to food safety only when the status quo is altered, for example, by a recall or outbreak (10).

The combined shopping and focus group data collected in the present study support a positive effect of training videos on participant knowledge and awareness of food safety risks in grocery stores, especially safe food storage temperatures, cleanliness and sanitation of food storage areas, and the use of temperature rather than visual or tactile methods as an indicator of safety. Several participants noted that storage temperature information was repeated across several videos, and one participant stated that the repetition helped them to remember the correct storage temperatures. Repetition has been cited as a method for reinforcing food safety messages (18, 45 ), and the findings in the present study support the use of repetition in interventions such as training videos to effectively increase consumer recollection of food safety information. However, the impact of the videos on the ability of consumers to identify the same actual risks as identified by the EHS is less clear. Participants may have grasped key food safety concerns from the videos in the meat and poultry department more easily than in other departments; experimental group participants were more likely than the control participants to identify at least one food safety risk in the meat and poultry department that was also identified by the EHS. Although the videos targeted package integrity and storage temperatures in the meat and poultry department, which were two issues identified by experimental group participants in agreement with the EHS post-intervention, the greater agreement in the meat and poultry department could be a result of more risks being present in this department during the November shopping session.

The higher number of perceived than actual food safety risks, especially in the produce department, may be associated with a tendency for consumers to attribute visible quality indicators, such as bruising, spoilage, and visible dirt on fresh produce, with food safety issues (12, 21 ). For example, participants reported thinking a food was unsafe based on an "unappealing" appearance (21). de Hooge et al. (8) came to a similar conclusion when they investigated consumers' preferences for optimal products (standard appearance or best-before dates farther in the future) compared with suboptimal products (visual defects, dented packaging, or past best-before dates). When given the choice to purchase or not purchase from a supermarket an apple with a brown spot, an oddly shaped cucumber, and/or biscuits or fruit juice with damaged packaging, which were considered suboptimal products by the research team, de Hooge et al. found that only 2.6, 26, 6.2, and 3.3 of the 2,109 consumers selected the apple with the brown spot, the oddly shaped cucumber, the damaged biscuits, and/or the damaged fruit juice, respectively. These findings suggest that consumers may view grocery store products with visual defects, such as a brown spot, odd shape, or damaged packaging, as "unattractive, unsafe to eat, and badtasting" (8).

Overall, participants identified higher numbers of both actual and perceived risks in the produce, deli, and meat and poultry departments than in the seafood department and checkout area. These departments remained in the top three even after focusing on only actual risks identified by the experimental group during post-intervention shopping. Many factors are likely to influence this pattern, including a strong focus on easily identifiable food safety risks in these departments, the larger size of these departments at the stores shopped compared with the seafood department and checkout area, and participant fatigue toward the end of the survey (seafood and checkout were the last two departments in the survey).

Relatively few actual or perceived food safety risks were identified at checkout by shoppers and the EHS. No guidance regarding mitigating food safety risks for the checkout area of grocery stores appears in the 2013 FDA 
Food Code or any previous iterations; the only information available relates to standard operating procedures for cleaning and sanitation in the Code of Federal Regulations (21 CFR 117.35 and 117.37) (39). Checkout area conveyor belts can be a source of contamination in grocery stores (44). Although Yan (44) no foodborne pathogens in this area, high microbial populations were found on all of the conveyor belts tested, some with high levels of coliforms, indicating poor hygiene and the potential for foodborne pathogen contamination. Because the checkout area can harbor food safety risks, such as cross-contamination from inadequate cleaning and sanitation of conveyor belts and scales, food safety experts and food retailers should further explore risk mitigation strategies specific to the checkout process and associated surface areas (44).

Relatively few actual or perceived food safety risks were reported in the seafood department. At least two of the stores in the study had small seafood departments, and the seafood department at one store did not open until later in the morning, often after participants had already finished their shopping sessions. These factors may have impacted the number of food safety risks reported by participants and by the EHS. Further study is needed to investigate these patterns.

The results from the focus groups corroborated several of the themes identified in our previous study (21), namely consumers' associations between store cleanliness and sanitation and store age and safety and a concern for how food is handled beyond what shoppers are able to observe, such as what occurred before they shopped and before the food was visible on the shelf. Retailers should consider the importance of these factors for attracting and retaining regular shoppers. Because of their increased awareness of potential food safety issues in grocery stores after viewing the intervention videos, experimental group participants may have perceived the stores they visited during their November shopping trip as being relatively worse in terms of managing food safety. This assumption is based on participants' comments during the focus group meetings that because of their new understanding of food safety, they may be less likely to shop at stores where they observed poor food safety practices, especially the stores they visited on their second shopping session.

The present study has some limitations. The low number of shoppers per time block for each shopping session made it difficult to interpret the statistical significance of numbers of food safety risks identified among participants visiting the same store at approximately the same time. Because participants were not shopping in the stores at the exact same time, they may have witnessed different types and severities of issues impacting food safety. For example, one participant may have witnessed an employee failing to wash hands when it would have been appropriate to do so, whereas another participant may have missed the opportunity to observe that same behavior. The expert also evaluated the store minutes before the participants entered, albeit within the same 3-h window, which may have affected agreement between the expert and shoppers relative to the numbers and types of food safety risks identified. The survey design also may have confused some participants because they were asked to provide additional information in a final open-ended question for each store department. A photograph provides a snapshot in time within a store, and another limitation is that participants may have missed the exact instance they were looking to record. We did not review photographs with participants to understand their reasons for recording what they did and relied on their comments only. Responses to the openended questions were included as secondary data and were not tallied as actual or perceived food safety risks. Prior knowledge of food safety in general may have impacted the results, despite attempts to screen out individuals who had participated in our previous studies and/or who had prior food handling experience, knowledge, or training. A research team member error when assigning experimental and control group participants during the recruitment process led to a greater-than-expected difference in participant numbers between the experimental and control groups despite the exclusion of equal numbers of outliers in these groups from the data analysis. The potential risks that can be observed in a store at any given time changes throughout the day, which may explain why the experimental and control groups were statistically similar regarding the number of actual food safety risks identified at baseline yet were significantly different at the post-intervention session between but not within their respective groups. The participant store assignment, date, and time was not controlled at either the baseline or postintervention shopping sessions. Participants were scheduled for their first session based on availability, and participants did not necessarily visit the same store at the same time of day or on the same day of the week during their second shopping session as they did on their first shopping session due to scheduling challenges.

Additional limitations impacted the quality and content of the intervention videos. The EHS may have identified risks that were not explicitly described in the intervention videos because the EHS had prior training in identifying food safety risks in food retail environments. Although the training videos were reviewed by the EHS and informed by consumer-based data, including the USDA Risk Factor Study (38), the 2016 USDA Food Safety Survey (20), and the 2013 FDA Food Code (39), consumers did not directly provide input into the development of the videos and the videos were not pilot tested with consumers because of time constraints. The design and layout of individual grocery stores where participants shopped differed from the store shown in the video, which also may have impacted 
the number of food safety risks identified by participants. Despite some minor limitations in the scope and design of this study, the findings provide insight into consumer perceptions of food safety risks at grocery stores and the utility of short videos specifically tailored to inform consumers of some practices and scenarios that may lead to increased food safety risks.

\section{CONCLUSIONS}

Grocery stores provide services to customers similar to those found in traditional food service establishments, such as offering prepared foods including to-go foods, ready-toeat meals, and hot and cold bar items. Retail food stores abide by similar, if not identical, safe handling practices as do retail food service operations as prescribed by the U.S. FDA Food Code (39). Yet, consumers may not recognize the potential for food safety risks at grocery stores, thus elevating the risk for foodborne illness. This study advanced the body of research on consumer perceptions of food safety in retail food store environments through real-time in situ consumer data collection with a mobile electronic device. Our results validate those of Levine et al. (21) and others (28) indicating consumer inability to effectively identify risky situations and discern differences between actual and perceived risk factors that may impact the safety of foods at retail establishments. Short educational videos can be devised targeting specific factors that can promote pathogen presence, persistence, and/or portability in grocery stores. These videos can be utilized to help improve consumer identification of food safety issues while food shopping. The approach in this study provided an opportunity to enlist shoppers as data collectors (i.e., citizen scientists) in a more controlled way and justification for considering the viewpoint of the consumer when developing educational interventions for reducing foodborne illness risk at food retailers. Additional research is needed to provide further insight into these results and their practical implications.

\section{ACKNOWLEDGMENTS}

The authors thank Publix Super Markets (Lakeland, FL) for their commitment to food safety and their collaboration with NCSU on the intervention portion of this project. We also thank Chris Rupert, Minh Duong, Sarah Cope, and Debbie Stroud (NCSU) for assisting with the intervention videos. We also thank Celia Herring, Eleanor Frederick, Lindsey Doring, Chris Rupert, Minh Duong, Sarah Cope, and Mary Yavelak (NCSU) for data collection. Mention of trade names or commercial products in this article is solely for the purpose of providing specific information and does not imply recommendation or endorsement by the USDA.

\section{REFERENCES}

1. Behnke, C., and S. Seo. 2015. Using smartphone technology to assess the food safety practices of farmers' market foodservice employees. J. Foodservice Bus. Res. 18:1-19.

2. Behnke, C., S. Seo, and K. Miller. 2012. Assessing food safety practices in farmers' markets. Food Prot. Trends 32:232-239.

3. Braun, V., and V. Clarke. 2006. Using thematic analysis in psychology. Qual. Res. Psychol. 3:77-101.

4. Brown, L. G., E. R. Hoover, D. Ripley, B. Matis, D. Nicholas, N. Hedeen, and B. Faw. 2016. Retail deli slicer cleaning frequencysix selected sites, United States, 2012. Morb. Mortal. Wkly. Rep. 65:306-310. Available at: http://dx.doi.org/10.15585/mmwr. mm6512a2. Accessed 3 July 2019.

5. Centers for Disease Control and Prevention. 1996. Surveillance for foodborne-disease outbreaks-United States, 1988-1992. Morb. Mortal. Wkly. Rep. 45(SS-5):1-55.

6. Centers for Disease Control and Prevention. 2018. National Outbreak Reporting System. Available at: https://wwwn.cdc.gov/ norsdashboard. Accessed 3 July 2019.

7. Choi, J., H. Norwood, S. Seo, S. A. Sirsat, and J. Neal. 2016. Evaluation of food safety related behaviors of retail and food service employees while handling fresh and fresh-cut leafy greens. Food Control 67:199-208.
8. de Hooge, I. E., M. Oostindjer, J. AschemannWitzel, A. Normann, S. M. Loose, and V. L. Almli. 2017. This apple is too ugly for me! Consumer preferences for suboptimal food products in the supermarket and at home. Food Qual. Pref. 56:80-92.

9. Food Marketing Institute. 2015. U.S. grocery shopper trends: executive summary. Available at: https://www.fmi.org/docs/defaultsource/document-share/fmitrends15-execsumm-06-02-15.pdf. Accessed 3 July 2019.

10. Food Marketing Institute. 2017. U.S. grocery shopper trends: food retail implications for U.S. grocery shopper trends. Presented online 18 July 2017 . Available at: https://www.fmi. org/docs/default-source/webinars/trends2017-webinar-7-18-2017.pdf. Accessed 3 July 2019.

11. Frewer, L. J., C. Howard, D. Hedderley, and R. Shepherd. 1996. What determines trust in information about food-related risks? Underlying psychological constructs. Risk Anal. 16:473-486.

12. Grunert, K. G. 2002. Current issues in the understanding of consumer food choice. Trends Food Sci. Technol. 13:275-285.

13. Grunert, K. G. 2005. Food quality and safety: consumer perception and demand. Eur. Rev. Agric. Econ. 32:369-391.
14. Hansen, J., L. Holm, L. Frewer, P. Robinson, and P. Sandøe. 2003. Beyond the knowledge deficit: recent research into lay and expert attitudes to food risks. Appetite 41:111-121.

15. Hogg, R. V., E. A. Tanis, and D. L. Zimmerman. 2014. Probability and statistical inference, 9th ed. Pearson, New York.

16. International Food Information Council. 2012. Food safety - a shared responsibility. Posted 4 September 2012, last updated 23 May 2014. Available at: https://www. foodinsight.org/blogs/food-safety-sharedresponsibility. Accessed 3 July 2019.

17. International Food Information Council. 2018. Food \& health survey. Available at: https://www.foodinsight.org/2018-foodand-health-survey. Accessed 3 July 2019.

18. Jacob, C., L. Mathiasen, and D. Powell. 2010. Designing effective messages for microbial food safety hazards. Food Control 21:1-6.

19. Janjić, J., J. Ćirić, M. Bošković, D. Šarčević, M. Popović, and M. Ž. Baltić. 2017. Consumer responsibility for food safety. Res. Agric. 3:1-10.

20. Lando, A., L. Verrill, S. Liu, and E. Smith. 2016. Food safety survey: executive summary. U.S. Food and Drug Administration. Available at: https://www.fda.gov/ downloads/food/foodscienceresearch/ consumerbehaviorresearch/ucm529453.pdf. Accessed 3 July 2019. 
21. Levine, K., M. Yavelak, J. B. Luchansky, A. C. S. Porto-Fett, and B. Chapman. 2017. Consumer perceptions of the safety of readyto-eat foods in retail store settings. J. Food Prot. 80:1364-1377.

22. Lipcsei, L. E., L. G. Brown, E. R. Hoover, B. V. Faw, N. Hedeen, B. Matis, D. Nicholas, and D. Ripley. 2018. Retail deli slicer inspection practices: an EHS-Net study. J. Food Prot. 81:799-805.

23. Lubran, M. B., R. Pouillot, S. Bohm, E. M. Calvey, J. Meng, and S. Dennis. 2010. Observational study of food safety practices in retail deli departments. J. Food Prot. 73:1849-1857.

24. Luchansky, J. B., A. C. S. Porto-Fett, and B. Chapman. 2016. A shopper's eye view of food safety at retail stores: lessons from photographs taken while grocery shopping. Food Prot. Trends 37:30-42.

25. National Science Foundation. 2 September 2015. Food safety is a shared responsibility. 2015. Available from: http://www.nsf. org/newsroom/food-safety-is-a-sharedresponsibility. Accessed 3 July 2019.

26. North Carolina Department of Health and Human Services, Division of Public Health Environmental Health Section. 2013. Food establishment inspection report. Available at: https://ehs.ncpublichealth.com/docs/ forms/FoodInspectionForm-Mar13.pdf. Accessed 3 July 2019.

27. Painter, J. A., R. M. Hoekstra, T. Ayers, R. V. Tauxe, C. R. Braden, F. J. Angulo, and P. M. Griffin. 2013. Attribution of foodborne illnesses, hospitalizations, and deaths to food commodities by using outbreak data, United States, 1998-2008. Emerg. Infect. Dis. 19:407-415.

28. Paulin, C., I. E. Lofgren, and L. F. Pivarnik. 2017. An assessment of consumer food safety handling practices of produce at grocery stores in Rhode Island. Food Prot. Trends 37:99-106.

29. Ringquist, J., T. Phillips, B. Renner, R. Sides, K. Stuart, M. Baum, and J. Flannery. 2016. Capitalizing on the shifting consumer food value equation. Deloitte analysis. Available at: https://www2.deloitte.com/content/ dam/Deloitte/us/Documents/consumerbusiness/us-fmi-gma-report.pdf. Accessed 3 July 2019.
30. Rowell, A. E., M. Binkley, C. Alvarado, L. Thompson, and S. Burris. 2013. Influence of food safety training on grocery store employees' performance of food handling practices. Food Policy 41:177-183.

31. Rutledge, S. 2015. Frank Yiannas: food safety is a shared responsibility. Stop Foodborne Illness. Posted 3 November 2015. Available at: http://www.stopfoodborneillness.org/ candc_frank-yiannas_food-safety-hero/. Accessed 3 July 2019.

32. Slovic, P. 1993. Perceived risk, trust, and democracy. Risk Anal. 13:675-682.

33. Slovic, P., B. Fischhoff, and S. Lichtenstein. 1980. Facts and fears: understanding perceived risk, p. 181-216. In R. C. Schwing and W. A. Albers, Jr. (ed.), Societal risk assessment: how safe is safe enough? Springer, Boston.

34. Stewart, D. W., and P. N. Shamdasani. 2014 Focus groups: theory and practice, $3 \mathrm{rd}$ ed. Sage, Thousand Oaks, CA.

35. Sue, V. M., and L. A. Ritter. 2012. Conducting online surveys, $2 \mathrm{nd}$ ed. Sage, Thousand Oaks, CA.

36. Urbaniak, G. C., and S. Plous. 2013. Research randomizer, v. 4.0. Available at: http://www. randomizer.org. Accessed 3 July 2019.

37. U.S. Census Bureau. 2017. QuickFacts. Available at: https://www.census.gov/ quickfacts/fact/table/US/INC110217. Accessed.

38. U.S. Food and Drug Administration. 2010. FDA trend analysis report on the occurrence of foodborne illness risk factors in selected institutional foodservice, restaurant, and retail food store facility types (1998-2008). Available at: https://wayback. archive-it.org/7993/20170406022950/ https://www.fda.gov/Food/ GuidanceRegulation/RetailFoodProtection/ FoodborneIllnessRiskFactorReduction/ ucm223293.htm. Accessed 3 July 2019.

39. U.S. Food and Drug Administration, Center for Food Safety and Applied Nutrition. 2013. FDA food code. Available at: http:// www.fda.gov/Food/GuidanceRegulation/ RetailFoodProtection/FoodCode/. Accessed 3 July 2019
40. Vandeputte, E. G., L. F. Pivarnik, J. Scheinberg, R. Machado, C. N. Cutter, and I. E. Lofgren. 2015. An assessment of food safety handling practices at farmers markets in Rhode Island using a smartphone application. Food Prot. Trends 35:428-439.

41. Van Loo, E. J., S. C. Ricke, S. R. Milillo, S. Seideman, and P. G. Crandall. 2010. Consumer food safety perceptions of readyto-eat deli foods in Northwest Arkansas. Food Prot. Trends 30:635-643.

42. Verbeke, W., L. J. Frewer, J. Scholderer, and H. F. De Brabander. 2007. Why consumers behave as they do with respect to food safety and risk information. Anal. Chim. Acta. 586:2-7

43. Webster, K., C. Jardine, S. B. Cash, and L. M. McMullen. 2010. Risk ranking: investigating expert and public differences in evaluating food safety hazards. J. Food Prot. 73:18751885.

44. Yan, Z. 2009. Analysis of microbial populations present on checkstand conveyor belts in grocery stores. Presented at the IAFP Annual Conference, 14 July 2009. Available at: https: //www.scribd.com/ fullscreen/59628168?access key=key5ilmx6ul0kdbol3s2zh. Accessed 3 July 2019.

45. Yiannas, F. 2015. Food safety $=$ behavior: 30 proven techniques to enhance employee compliance. Springer, New York.

46. Yu, H., J. A. Neal, and S. A. Sirsat. 2018. Consumers' food safety risk perceptions and willingness to pay for fresh-cut produce with lower risk of foodborne illness. Food Control $86: 83-89$.

47. Zanin, L. M., D. T. da Cunha, V. V. de Rosso, V. D. Capriles, and E. Stedefeldt. 2017. Knowledge, attitudes and practices of food handlers in food safety: an integrative review. Food Res. Int. 100:53-62. 